\title{
1-Aminocyclopropane-1-Carboxylate (ACC) Deaminase Genes in Rhizobia from Southern Saskatchewan
}

\author{
Jin Duan • Kirsten M. Müller • Trevor C. Charles •
} Susanne Vesely $•$ Bernard R. Glick

Published online: 19 February 2009

(C) Springer Science + Business Media, LLC 2009

\section{Erratum to: Microb Ecol \\ DOI 10.1007/s00248-008-9407-6}

In Table 1 of the original version of this article, there were mistakes on the Accession numbers under the third column "ACC deaminase gene". Correct Table 1 is given here.

The online version of the original article can be found at http://dx.doi. org/10.1007/s00248-008-9407-6.

J. Duan $(\bowtie) \cdot$ K. M. Müller · T. C. Charles · S. Vesely •

B. R. Glick

Department of Biology, University of Waterloo,

200 University Avenue West,

Waterloo, ON N2L 3G1, Canada

e-mail: jduan@sciborg.uwaterloo.ca 


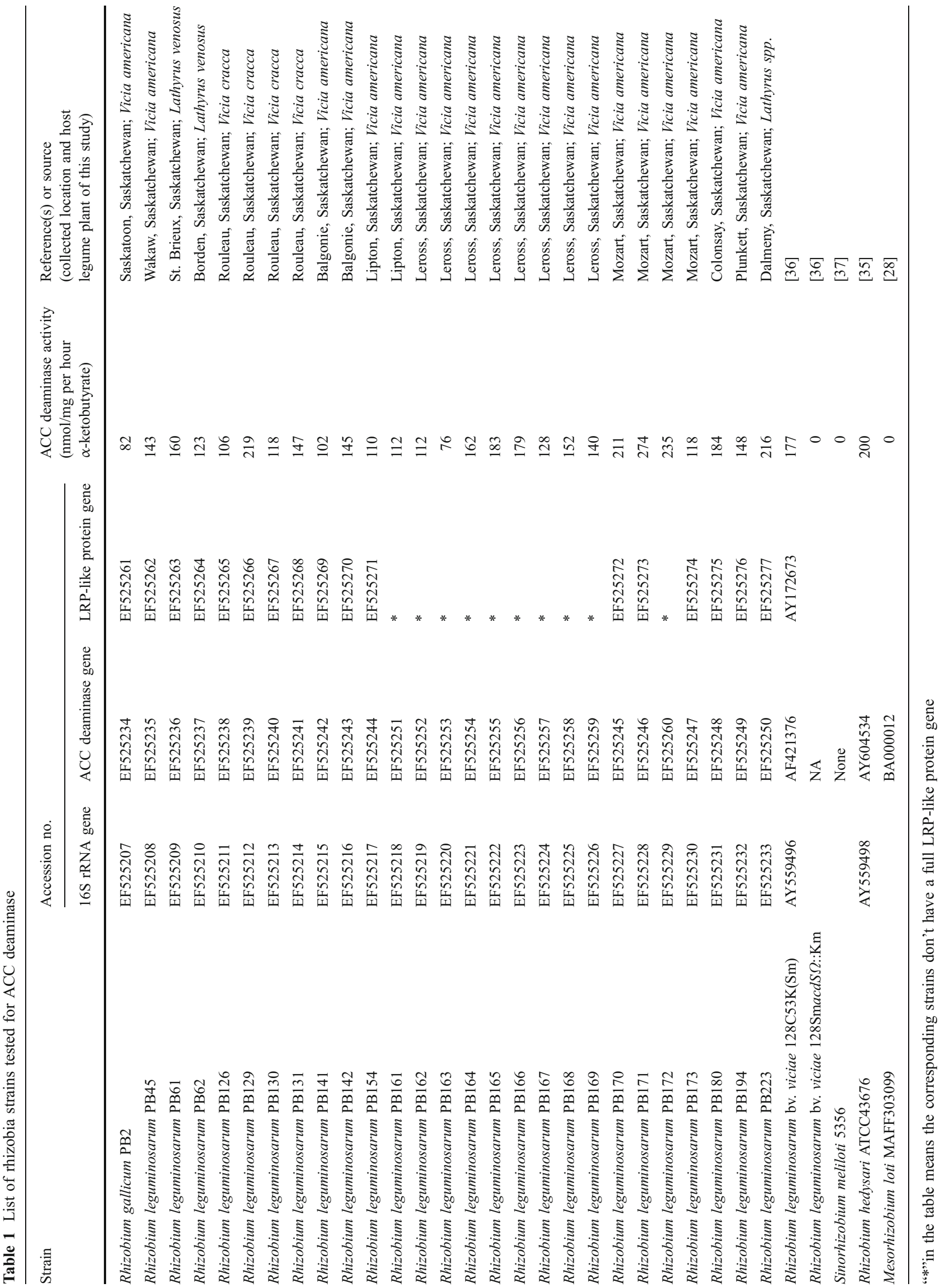

